\title{
Research on the Influences of Market Conditions, Culture and Politics on Market Timing
}

\author{
Zhuobin $\mathrm{He}^{1, \mathrm{a}}$ \\ Cultural Industrial Management, Jinan University, Guangzhou, Guangdong, China, 528313 \\ Corresponding author's e-mail: angela@cas-harbour.org
}

\begin{abstract}
A correct judgment of the market consists of comprehensive analysis in different aspects. The market timing is one of those important aspects, so this paper focuses on the market timing and proposes three factors which will play the key roles. This study aims to examine the influence of market conditions, culture and politics on the market timing, thus finding out the relationship between these three factors and the market, and giving some advice to the entrepreneurs on how to assess the suitable market timing. The analysis results of this research are as follows. First of all, the increasing income of the customers makes the market capacity increase, or the market will decrease. For example, China has become the second largest economy in the world. The consumption desires of Chinese people is growing as fast as their incomes. Alibaba filled people's demand for fast consumption desires, so it becomes one of the best online e-commerce companies in the world. Besides, because of the background and cultural environment, the customers from different countries have different consumption behaviors. From the case study of pick-up truck, it can be concluded that the negligence of cultural factors can lead to the failure of marketing. Furthermore, the policies of the government play the role as guidance in the market. Taking ceramic industry as an example, the environmental protection policy eliminates the high-pollution enterprises and promotes structure optimization of the ceramic industry in Guangdong, China. Therefore, entrepreneurs should pay more attention to the influences of these three factors, in order to make the best decision for their enterprises.
\end{abstract}

Keywords: Market conditions, culture, politics, entrepreneur, marketing time

\section{INTRODUCTION}

The market is changing every second. It is difficult to grasp the pulse of the market on people's own. It requires some ways to catch the key information of the market. Market conditions, culture and politics are good ways to find out the secrets of the marketing. This study will give three examples to discuss how these three factors influence the market timing. According to the particularity of the research object, this study adopts case analysis of different influencing factors, and then summarizes the methods to seize the right market opportunity. Through collecting information and reading literature on the Internet, this study analyzes the company operation of Alibaba Group, Ford Company and New Pearl Group in special period. If any factor is ignored, the judgment of market timing may produce great errors, which may affect the company's business strategy and even ruin the company's future. When people understand and use all the information the three factors showed, the market timing can be easily figured out.

\section{INTRODUCTION TO THE SELECTED COMPANIES}

In order to better analyze the influence of market factors, cultural factors, and political factors on market timing, this study looks for some special strategic decisions of successful companies in a special period to more specifically show the importance of market timing.

Among them, Alibaba group is one of the most successful e-commerce companies in China. It can well show that the success of a company cannot be separated from the sense of crisis and market acumen. The right market strategy is healthier and has more development potential than the strategy of blindly pursuing large investment and high profit.

Ford is one of the world famous automobile brands, but a misjudgment of China made it realize the importance of judging the cultural background of the market. The right market opportunity has nothing to do with the enterprise, only with the market.

In the face of the sudden environmental protection policy of Guangdong Province, New Pearl Group's timely choice led the company walk out of the predicament and towards success. Using the information of government policy, we 
can better grasp the market dividend and achieve extraordinary results.

\section{METHODOLOGY}

The methodology used in this study is case study. The research object of this study is the market, cultural and political factors in the market. These three research objects are relatively macroscopic and objective. Case study is more efficient in this study.

With limited time and cost, this methodology can analyze Alibaba, Ford and New Pearl Group specifically. The successful cases of the industry leaders can better persuade entrepreneurs than the academical theories.

As a result, entrepreneurs are more likely to accept the suggestions in this paper and pay attention to the influence of market, cultural and political factors on market timing.

\section{MARKET FACTOR}

Market factor is crucial for entrepreneurs to make decisions, because every small change in the market can make a big difference to the whole marketing strategy. Customers, channels, business partners and revenue all are important both in the enterprises and the whole market. Customers can give the most information among them. All customer behaviors, like thoughts, desires and demands, are useful for the entrepreneurs who are trying to study the market. Once entrepreneurs figure out the information of the customers provided, they can grab decisive occasion, which others cannot. Alibaba Group has set a good example in this area. Taobao, founded in 2003, is one of Alibaba's main businesses, which provides consumers with both a sense of participation and personalized shopping experience through big data analysis. The enterprises on the platform are mainly self-employed and small enterprises. Consumers can obtain highly relevant and attractive content as well as real-time updates from the company to master product and trend information. At the same time, consumers can also interact with other consumers or favorite companies and brands [1]. The emergence of Taobao met the needs of customers in the Internet at that time. And its innovative way makes more people experience the convenience of online shopping. It perfectly shows how to use the information in the market and catch the correct market timing.

What is more, Alibaba's attention to the market never diminished. It found that the payment was not convenient enough for the customers. Thus, in December 2004, Alibaba launched the third party online payment platform of Alibaba group affiliated company, Alipay. The emergence of Alipay has optimized the payment experience of customers, making Taobao's online shopping platform more systematic. Let more customers add trust and loyalty to Alibaba.

The same stories could be found in Alibaba Group's subsidiaries. Founded in 2008, Tmall was committed to providing consumers with high-quality shopping experience of brand products. A number of international and Chinese local brands and retailers have opened stores on Tmall. Compared with the previous Taobao, it optimized the sources and channels of products and brands, and made more consumers feel comfortable during the shopping.

Ant Financial Services Group focused on serving Tmall and micro businesses as well as ordinary consumers, and filled the gap of micro businesses and ordinary consumers for micro credit services. Ant Financial Services Group built an open ecosystem, and gathered other financial institutions, to provide financial support for the society.

Rookie Network was also a business of Alibaba group, which was dedicated to meet the current and future needs of China's online and mobile commerce industry in terms of logistics. The logistics data platform operated by Rookie Network utilized the capacity and ability of logistics partners to realize large-scale transactions between businesses and consumers. In addition, Rookie Network used data insight and technology to improve the efficiency of the entire logistics value chain [2].

From all the things Alibaba did, people can see a customer-oriented market strategy. Considering and optimizing each issue from the customer's perspective can make it a better company. This kind of market-oriented competitive strategy is very useful to grasp the market opportunity. Good customer analysis and market research will help entrepreneurs make the right decision of market timing with half of the effort.

\section{CULTURE FACTOR}

Culture factor is often overlooked by entrepreneurs. Many entrepreneurs attach great significance to economic factors when they enter the market, whereas they do not attach enough importance to culture factor. The role of culture background of the target group in the market is just like the coral in the sea. It is not obvious but it is very important. The culture of the local market greatly affects the preference of customers for products. As a result, the products in different countries and regions usually cannot be sold with the same business thinking. Ignoring culture factor would lead to failure in market timing judgment.

Due to the cultural background, market conditions varies from regions to regions, and the difference is particularly obvious in the automotive market. As a classic best-selling model, pickup truck is very popular with customers all over the world. Among them, Ford's pick-up truck is the best one, which is deeply loved by the Americans. Here are some reasons.

Road is a symbol of freedom between the Americans. At the beginning of the founding of the United States, it experienced the era of the western development and the period of the high-speed development of the American highway. Therefore, car also inherits part of the spiritual connotation of the highway and carries the spirit of the American people's pursuit of dreams and freedom. As a result, the pick-up truck is very popular in the U.S. with its affordable price and multi-purpose use, and Ford has also achieved great success in the U.S. market [3]. 
After Ford's great success, a failed market judgment taught the company a profound lesson. Before entering the Chinese automobile market, Ford planned to choose a representative pickup truck model to promote in the Chinese market. Ford's judgment at that time was based on the fact that China had a larger population than the United States and the market demand was huge. High cost performance pickups are sure to be popular. Ford failed, because pickup trucks are not popular in China today[4].

So what are the reasons for the failure? In China, pickup trucks do not conform to people's cognition of private cars. In addition to taking the car as a substitute for walking, the car is also a symbol of people's status. Therefore, people prefer high-end cars to high-quality cars. This cultural background makes pickup trucks serve only as trucks for transporting goods in China. Therefore, the market of pickup in China is very small. Hence, Ford's pickup is doomed to fail in China.

To sum up, people should pay full attention to the cultural background of each regional market and the analysis of culture factor. Entrepreneurs will gain great advantages in the future production promotion and marketing, so as to accurately judge the right market opportunity and seize the opportunity in the market competition. Then they can find out the correct market timing.

\section{POLITICS FACTOR}

Political factors often play the role of wind vane in the market. Political factors include many aspects, the following is mainly from the policy aspect. In addition to the guiding role, policies sometimes have the role of compulsory intervention in the market, so as to achieve the purpose of optimizing the market. By actively knowing political information and implementing government policies, people can accurately control market timing.

The ceramic industry in China can be taken as an example. In China's early rapid economic development, we found that they ignored environmental protection. Therefore, around 2010, local governments successively issued environmental protection policies to optimize people's living environment and to meet the requirements of emission reduction and emission limitation for high polluting enterprises. Ceramic industry belongs to the high pollution industry, and was also one of the key optimization and restriction industries. After the introduction of government policies, many ceramic companies were not adapted to the sudden restrictions. The whole industry is facing great challenges[5].

To implement government policies, entrepreneurs faced two choices at that time. First, they optimized or reformed the company's factory in accordance with the environmental protection requirements of national standards. Second, they transferred the industrial chain and chose industries other than ceramics to continue to operate their own businesses. In front of these two kinds of decision-making, entrepreneurs helped the government realize the structural optimization of the ceramic industry invisibly, which not only eliminated some enterprises that were lack of competitiveness, but also enabled the remaining enterprises to meet the requirements of environmental protection.

Under this policy, if entrepreneurs could judge the intention of the government in time, they could judge the right market opportunity. New Pearl Group was one of the top ten ceramic enterprises in China. Under this policy, it reduced the capital chain of ceramic industry, and began to inject capital into the real estate market to expand its business scope. After that, it successfully achieved success in the real estate industry and opened the group operation of new Pearl enterprise. This was a perfect market opportunity[6].

It is worth mentioning that the environmental protection policy at that time not only optimized and reformed some high pollution enterprises, but also improved the economic structure and urban environment of some cities. There were many high pollution industries in Guangdong, Hong Kong and Macao Bay area before. However, since the environmental protection policy had been implemented, many high polluting enterprises in the urban agglomeration of Guangdong, Hong Kong and Macao evacuated and moved to cities with lower production costs. It not only optimized the economic structure and beautifies the environment of Guangdong, Hong Kong, Macao and other economically developed areas, but also helped other cities develop their economy.

Therefore, the correct interpretation of policies can not only help entrepreneurs to correctly judge the market opportunity, avoid additional economic losses, but also help society and cities become better.

\section{CONCLUSIONS AND IMPLICATIONS}

To sum up, the right market timing is inseparable from the correct interpretation of market, cultural and political factors. Market factor is the centre part of the market timing, and the information provided by market factor can help entrepreneurs have a comprehensive understanding and value judgment of the market. Cultural factor is the core of the market, so it is necessary to carefully analyze the cultural background and environment of the market in various countries and regions. Ignoring this factor is likely to lead to the final failure of market timing. Politics factor is the wind vane of the market. Following the requirements of government policies can make better use of the information contained in policies to grasp the right market opportunity. From this perspective, this research can provide helpful information for entrepreneurs.

Besides, the current research contains some shortages, such as the lack of data. As a result, only a few examples and data are provided. The research time is also limited. And the data collection is confined to the source on the Internet. Hence, the analysis result can be biased to the limitations of this research. A more accurate research in market timing will be conducted in the future to further verify this result.

\section{ACKNOWLEDGMENT}


First and foremost, I would like to show my deepest gratitude to my teachers and professors in my university, who have provided me with valuable guidance in every stage of the writing of this thesis. Further, I would like to thank all my friends and roommates for their encouragement and support. Without all their enlightening instruction and impressive kindness, I could not have completed my thesis.

\section{REFERENCES}

[1] M. Glowik. 4.1 case study: Alibaba group. Global Strategy in the Service Industries: Dynamics, Analysis, Growth, 2017, 96.

[2] L. Huang, G. Hu, X. Lu. E-business ecosystem and its evolutionary path: the case of the Alibaba group in China. Pacific Asia Journal of the Association for Information Systems, 2009, 1(4).

[3] C. Liu, Y. Wei, L. Zhang. Licensing or not Licensing? A Pilot Study on Examining the Apparel Extension of Auto Brands Ford and Jeep in China Market. Chinese Consumers and the Fashion Market. Singapore: Springer, 2018, pp. 145-168.

[4] P. Lassere, M. Zeng. Guangzhou Honda Automobile Co., Ltd: Honda's Entry into the China Car Market. INSEAD Case Study, 2002.

[5] M. Russo. The ceramic industrial district facing the challenge from China. Dipartimento di Scienze Sociali, Cognitive e Quantitative. Università degli Studi di Modena e Reggio Emilia, 2004.

[6] K. Zhang, Z. Wen. Review and challenges of policies of environmental protection and sustainable development in China. Journal of environmental management, 2008, 88(4), pp. 1249-1261. 